\title{
RESENHA
}

\section{SAVIANI, Dermeval. Sistema Nacional de Educação e Plano Nacional de Educação: significado, controvérsias e perspectivas. - 2. ed. rev. e ampl. - Campinas, SP: Autores Associados, 2017.}

\author{
Luciano Francisco dos Santos, Andrezza Maria Batista do Nascimento Tavares \\ Instituto Federal de Educação, Ciência e Tecnologia do Rio Grande do Norte - IFRN
}

DOI: $10.15628 /$ rbept.2019.8218

Artigo submetido em jan/2019 e aceito em mar/2019

\section{RESUMO}

Na resenha, objetiva-seapresentar, refletir e tecer uma narrativado livro "Sistema Nacional de Educação e Plano Nacional de Educação: significado, controvérsias e perspectivas",uma retrospectiva da ideia e do conceito de sistema e do plano nacional de educação. Surgiu na década de 30, pelos Pioneiros da Educação Nova, pelo Manifesto de 1932, na constituição de 1934. Entre os anos 1960 e 1990, na LDB 4.024/61 ea ditadura militar (1964-1985), silenciando o tema, voltou na Constituição de 1988.Na década de 90, no plano decenal educação para todos, em 1993,eno governo FHC, na LDB9.394/96 e o PNE (2001-2010), que fora vetado, quanto ao financiamento. No governo Lula, o projeto de 2010, e no governo Dilma-Temer, pela transformação do projeto de 2010 no PNE (2014-2024), e, dos retrocessos causados pelo golpe de 2016 e da PEC 95/2016. O livro é uma leitura indispensável aos educadores do Brasil.

Palavras-Chave: Dermeval Saviani. Sistema Nacional de Educação. Plano Nacional de Educação. Políticas Educacionais. Educação pública no Brasil.

\begin{abstract}
In the review, the objective is to present, reflect and weave a narrative of the book "National System of Education and National Plan of Education: meaning, controversies and perspectives", a retrospective of the idea and concept of system and national education plan. It emerged in the 1930s, by the New Education Pioneers, by the Manifesto of 1932, in the constitution of 1934. Between the 60s and 90s, LDB 4.024 / 61 and the military dictatorship (1964-1985), silencing the theme, Constitution of 1988. In the 1990s, in the ten-year education for all plan, in 1993, and in the FHC government, in LDB 9.394 / 96 and PNE (20012010), which had been vetoed in terms of funding. In the Lula administration, the 2010 project, and in the Dilma-Temer government, for the transformation of the 2010 PNE project (20142024), and the setbacks caused by the 2016 coup and the PEC 95/2016. The book is an indispensable reading for educators in Brazil.
\end{abstract}

Keywords: Dermeval Saviani. National System of Education. National Education Plan. Educational Policies. Public education in Brazil. 
O livro "Sistema Nacional de Educação e Plano Nacional de Educação: significado, controvérsias e perspectivas", segunda edição (2017), revisado e ampliado,(em comparação com a sua primeira, em 2014), ao esgotar todos os livros da primeira edição (com tiragem de cinco mil exemplares), agora, na segunda, se incorporou, como anexo, o texto integral do PNE (2014-2024), desta vez, após sua aprovação ${ }^{1}$. O que, na conjuntura atual do contexto social, político, econômico e educacional brasileiro, se faz necessário ler, refletir e compreender as implicações imediatas das reformas.

As ideias presentes no livro surgiu, como subsídios de cunho teóricometodológico que forma pensados, inicialmente, para os debates da II $\operatorname{CONAE}^{2}$ (2014), que teve por tema: "O PNE na articulação do Sistema Nacional de Educação: participação popular, cooperação federativa e regime de colaboração".

A obra foi escrita pelo Professor pesquisador Dermeval Saviani que possui graduação em Filosofia (1966) e doutorado em Filosofia da Educação (1971) pela Pontifícia Universidade Católica de São Paulo. Tendo em 1986, obtido o título de livre-docente, e, em 1995, cursado estágio Pós-Doutoral pela Università di Bologna - UNIBO (ITÁLIA). Atualmente, desenvolve pesquisa, ensino e extensão pela Universidade Estadual de Campinas, na qual, é Professor Emérito e aposentado. É Pesquisador Emérito do CNPq e Coordenador Geral do Grupo de Estudos e Pesquisas "História, Sociedade e Educação no Brasil" (HISTEDBR).

Após a preciosa leitura do livro, podemos advogar a importância do seu conteúdo, bem como da forma (clara e concisa) na qual fora escrito. Outrossim, consideramos uma leitura indispensável para àqueles que querem entender, por meio da compreensão políticas educacionais no Brasil, partindo das suas ações e intenções, desde as suas conceituações e concepções, chegando aos passos e descompassos, e, por fim, compreender os ranços e avanços, em seus limites e perspectivas.

Nesse sentido, a obra é fruto de uma vasta pesquisa bibliográfica e documental que começou no doutorado (1968), por meio do projeto

\footnotetext{
${ }^{1}$ No lançamento da primeira edição, o PNE atual se encontrava em fase de elaboração, debate e aprovação.

2 II Conferência Nacional de Educação. 
"Fundamentos para um sistema educacional", desenvolvido por meio da fundamentação filosófica dos conceitos de sistema e de sistema educacional, o que levara o autor, na época, a formular a hipótese da falta de um sistema educacional do Brasil. O que culminou na sua tese (1971) - "O conceito de sistema na Lei de Diretrizes e Bases da Educação Nacional", que fora transformada em livro (1973), intitulado - "Educação brasileira: estrutura e sistema".

Por meio dos seus escritos, nessa linha de pesquisa, participou efetivamente dos debates da política educacional brasileira. Com suas aulas, palestras e publicações sobre as reformas do ensino então fixadas na legislação federal, mesmo sendo ignorado (por cerca de 40 anos), continuou a alertar sobre a necessidade da formulação do Sistema Nacional de Educação e de um Plano Nacional de Educação. Depois de todo esse tempo, Dermeval Saviani ganhou destaque após a preocupação do Ministério da Educação (MEC) ao convocar uma $\operatorname{CONAE}^{3}$, realizada em 2010, que teve por tema - "Construção do Sistema Nacional Articulado de Educação". Após exposta essa breve síntese da sua elaboração, vamos aos conteúdos dos capítulos do livro.

No primeiro capítulo intitulado, "Significado de Sistema Educacional", discorre, analisar e disseca sobre o uso indevido do significado do termo sistema, e, depois, de forma mais abrangente, de sistema educacional. Destarte, apresentando os grandes equívocos: seja confundir sistema com estrutura, rede de escolas, conjunto de Leis que regem a educação e até mesmo, com o conjunto de pessoas que atuam nas atividades (fins e meios) da educação nacional. Após uma longa análise semântica, morfossintática, filológica e filosófica da palavra sistema, expõe o que não é sistema, e a seguir, descreve o que é sistema, de acordo com seus estudos, pesquisas e concepções, tendo como requisitos básicos: intencionalidade, unidade, variedade, coerência interna e coerência externa (p. 3). E, depois, descreve cada uma das exigências, apresentando seu sentido.

\footnotetext{
${ }^{3}$ Tal prática vem desde o Brasil imperial, no entanto, ocorreram sem meios e fins próprios a ouvir e atender os reais anseios da educação nacional, e, consequentemente, não logrou êxito na tentativa de construir um Sistema e um Plano Nacional de Educação. O que marca essa nova chamada é a sua real intencionalidade e periodicidade.
} 
O segundo capítulo, "Sistemas Nacionais de Ensino", apresenta, historicamente, o emprego do termo Sistema educacional, o que, na tentativa de abstração desses conceitos, chegou a se criar a disciplina (ou área de conhecimento) educação comparada, de cunho pedagógico, cujo objetivo foi estudar os sistemas nacionais de ensino. O que, produziu uma finalidade inversa da qual fora criada, pois passou-se a generalizar o termo sistema, configurado como termo primitivo (p. 14), e carente de definição, causando com sua polissemia, indefinições conceituais e conceptuais, repleto de imprecisões a cerca da expressão "sistema educacional".

No terceiro capítulo, como mote, "Obstáculos à construção do Sistema Nacional de Educação no Brasil', se discute sobre os obstáculos na tentativa de construção de Plano. Com isto, foi organizando, didaticamente, os entraves para o SNE e seus respectivos conceitos, concepções e implicações, são estes: os obstáculos econômicos, descrito pelo histórico abandono (do Brasil imperial aos dias atuais) do poder público na educação nacional, ou seja, de cunho material; os obstáculos políticos, retratados pelo falta de continuidade das políticas públicas em educação; os obstáculos filósofico-ideológicos, entendido como a mentalidade pedagógica, ou seja, da unidade entre a forma e o conteúdo das ideias educacionais; os obstáculo legais, concebido no campo das atividades legislativas pela (falta de) resistência da classe trabalhadora sobre a classe política, ocasionando a defesa dos interesses da educação. Posto que, sistematizar significa reunir, ordenar, articular elementos enquanto parte de um todo. E esse todo articulado é o sistema (p. 37).

E, em sua conclusão: persistência das dificuldades no contexto atual, retoma a exposição dos obstáculos do SNE e acrescenta a reflexão preocupante da aproximação de sistema com "enfoque sistêmico" por mais de um século, termo que tem sua origem na cibernética, ou seja, a concepção de sistema atrelado a algo mecânico, automático e robótico, e, portanto, tendo seu funcionamento sem a ação-reflexão-ação humana. Assim, com esse centenário de atraso na compreensão, conceituação e concepção de sistema, de fato, no Brasil ainda não atingiu o desiderato de construir um 
Sistema Nacional de Ensino ou se chegou a construir (na teoria), na prática ainda não entrou em funcionamento.

No quarto e propositivo capítulo, "Indicações para a Construção do Sistema Nacional de Educação no Brasil', traz a preocupação com os entraves(apresentados no capítulo anterior) para construção do SNE, apresentando as respectivos caminhos para a superação destes. A começar pela revisão de conceitos e definições dos termos já descritos, tais como: Sistema - unidade de vários elementos intencionalmente reunidos de modo que formem um conjunto coerente e operante (p. 43); Sistema Nacional de Educação- unidade dos vários aspectos ou serviços educacionais mobilizados por determinado país; Unidade - da variedade e não da unidade da identidade; Confederação - associação de países soberanos que articulam em função de determinados pontos de interesse comum em circunstâncias específicas, e, por último, Federação - união estável e permanente de estados autônomos, mas não soberanos.

Contudo, a diferença de poderes entre os entes federativos não é sinônimo de degraus de importância, ou seja, ter maior ou menor autonomia (no pacto). Traz as observações que a municipalização do ensino fundamental representou um retrocesso em si falando da qualidade da educação pública e que mesmo a mudança do FUNDEF para o FUNDEB não significou superação as reais desigualdades na qualidade da educação, ao contrário, reforçou as desigualdades. Adverte que o termo articulação antecede sistema educacional ${ }^{4}$, em se falando de organização e coerência interna, visto que o sistema que ainda precisa de articulação, pode, ser uma farsa, e, nem sistema ser, de fato.

E, por fim - as indicações: a) trate-se de construir um verdadeiro Sistema Nacional de Educação (p. 48); b) Como já foi explicado, o sistema só pode ser público (p. 50); c) A instância normativa e deliberativa do sistema será exercida por um órgão determinado que corresponde, hoje, ao Conselho Nacional de Educação ( $p$ 51) ; d) Na construção do Sistema Nacional de Educação, deve-se implantar uma arquitetônica a partir do ponto de

\footnotetext{
${ }^{4}$ Se referindo a presença do termo "articulado" no Título da CONAE (de 2010): "Construindo o sistema nacional articulado de educação: o plano nacional de educação, diretrizes e estratégias de ação."
} 
referência do regime de colaboração entre a União, os estados, distrito federal e os municípios...efetuando uma repartição das responsabilidades entre os entes federativos( p. 54); e) Sobre a forma de organização do sistema, além da organização administrativa ou funcional, considerar a organização pedagógica, considerando o trabalho como princípio educativo(p. 55), e, por fim, f) Deve-se considerar com toda a atenção e cuidado com o problema do conteúdo da educação a ser desenvolvida no âmbito de todo o sistema (p. 59).

No quinto capítulo (único com título e subtítulo), "Plano Nacional de Educação: esboço Histórico", revisita diversas referências bibliográficas na tentativa de construir uma revisão da literatura a cerca do surgimento da ideia de Plano Nacional de Educação. Começa a destacar que a defesa de um PNE remete ao Manifesto dos Pioneiros da Educação Nova, lançado em março de 1932. Que representaram uma visão da educação pública brasileira para além do seu tempo, ao prever que "[...] todos os nossos esforços, sem unidade de plano e sem espírito de continuidade, não lograram ainda criar um sistema de organização escolar, à altura das necessidades modernas e das necessidades do país." (MANIFESTO...,1984, p. 4075 , apud SAVIANI, 2017, p. 63, grifos nossos).

Com isso, a ideia de Plano ganhou destaque na Constituição Federal de $1934^{6}$, e no debate da educação por uns quatro anos seguintes, mas, depois, ganhou invisibilidade, só voltando ao destaque na primeira LDB 4.024, aprovada em 20 de Dezembro de 1961. Mas, em 1964 após o golpe militar, passou novamente a ser esquecido. Ressurgindo na década de 90, por meio da "Declaração Mundial sobe Educação para todos" ", a ponto de se criar (em 1993) o Plano Decenal de Educação para todos. Embora este plano, na prática, não saiu do papel. Assim, somente em 1996, na segunda LDB (9394/96), renasce o debate sobre o PNE, o que em 9 de Janeiro de 2001, foi aprovada a Lei oㅜ 10.172, que institui o Plano nacional de Educação,

\footnotetext{
${ }^{5}$ MANIFESTO dos Pioneiros da Educação Nova - 1932. Revista Brasileira de Estudos Pedagógicos. v. 65, n. 150, p. 407- 425, mai-ago. 1984.

${ }^{6} \mathrm{Na}$ alínea a do artigo 150, onde a União deveria fixar o Plano Nacional de Educação.

${ }^{7}$ Reunião realizada em Jomtien, na Tailândia. 
com nova vigência de dez anos. Este também serviu de mera carta de intenção, chegando inclusive, a ser vetado pelo então presidente $\mathrm{FHC}$.

No sexto capítulo intitulado, "Do projeto de 2010 ao PNE 2014-2024", ressalta que, basicamente, a diferença entre o PNE aprovado em 2001 e o projeto de 2010, é que, enquanto aquele tinha 295 metas, o de 2010 passou a ter, apenas 20. Depois de reformulado, este projeto serviu de base para 0 novo PNE (2014-2024), o qual se encontra em vigor.

No último capítulo intitulado, "Situação atual do Plano Nacional de Educação", se defende que, após o golpe jurídico-midiático-parlamentar que destitui a então presidente Dilma Rousseff, a execução do PNE atual também está sofrendo um verdadeiro xeque-mate da classe política do país, especialmente, com a PEC no 95/2016, que congela, por 20 anos os investimentos em educação e saúde, inclusive.

A conclusão, intitulada: "Dificuldade e perspectivas para a implantação do Sistema e do Plano Nacional de Educação", destaca as várias diversidades e adversidades que acabam por gerar dificuldades na execução do PNE atual, por exemplo de professores, quer seja nos grandes centros, quer seja nas cidades do interior e nos rincões do Brasil, obrigadas a sobreviver com remuneração, por vezes, menor que o salário mínimo vigente, sofrendo todo tipo de constrangimento (entre estes o material e o moral), submetidos aos mandonismos no chão da escola e o trabalho em condições precárias com crianças, jovens e adultos também em situação de miséria moral, econômica, política, social e cultural.

E, no anexo I, Intitulado, "Atividades do autor no processo de análise e discussão do Sistema nacional de Educação e do Plano Nacional de educação", se lista, em ordem cronológica, todas contribuições intelectuais do autor em relação o SNE e ao PNE, seja artigos, palestras, seminários, encontros, conferências, capítulos de livros ou livros.

E, por fim, no anexo II, Intitulado, "Plano Nacional de Educação - PNE 2014-2024", traz, o teor, na íntegra do PNE (2014-2024), conforme edição extra do Diário Oficial da União de 26/06/2014.

Notamos que, até na escolha do título - "Sistema Nacional de Educação e Plano Nacional de Educação: significado, controvérsias e 
perspectivas", o autor foi esclarecedor, pois é desses temas que aborda, na essência, o livro, quer seja pela ideia, conceitos e concepções, quer seja pela falta do entendimento, da existência e execução destes.

Se trata de uma retrospectiva da ideia e do conceito de Sistema Nacional de Educação e do Plano Nacional de Educação. Surgiu na década de 30, por meio do Movimento dos Pioneiros da Educação Nova, em 1932, e depois, na Constituição de 1934. Entre os anos 60 e 90, a LDB 4.024/61 e com a ditadura militar (1964-1985), silenciando o tema e na Constituição de 1988. Na década de 90, no Plano Decenal Educação para Todos, em 1993, e, depois, já no governo FHC, a segunda LDB 9.394/96 e o PNE de 20012010, que fora vetado. No governo Lula, o projeto de 2010, e no governo Dilma-Temer, pela transformação do projeto de 2010 no PNE (2014-2024), e, dos retrocessos causados pelo golpe jurídico-midiático-parlamentar e da PEC 95/2016. O livro é uma leitura indispensável aos educadores e a todos aqueles que querem compreender a História da educação no Brasil. 